\title{
Opioid-Dependent Anticipatory Negative Contrast and Binge-Like Eating in Rats with Limited Access to Highly Preferred Food
}

\author{
Pietro Cottone ${ }^{*, 1,2,3,4}$, Valentina Sabino ${ }^{1,2,4}$, Luca Steardo ${ }^{3}$ and Eric P Zorrilla ${ }^{* 1,2}$ \\ 'Committee on the Neurobiology of Addictive Disorders, The Scripps Research Institute, La Jolla, CA, USA; ${ }^{2}$ Harold L. Dorris Neurological \\ Research Institute, The Scripps Research Institute, La Jolla, CA, USA; ${ }^{3}$ Department of Human Physiology and Pharmacology, University of Rome La \\ Sapienza, Rome, Italy
}

\begin{abstract}
Binge eating and an increased role for palatability in determining food intake are abnormal adaptations in feeding behavior linked to eating disorders and body weight dysregulation. The present study tested the hypothesis that rats with limited access to highly preferred food would develop analogous opioid-dependent learned adaptations in feeding behavior, with associated changes in metabolism and anxiety-like behavior. For this purpose, adolescent female Wistar rats were daily food deprived ( $2 \mathrm{~h}$ ) and then offered 10 -min access to a feeder containing chow followed sequentially by 10 -min access to a different feeder containing either chow (chow/chow; $n=7$ ) or a highly preferred, but macronutrient-comparable, sucrose-rich diet (chow/preferred; $n=8$ ). Chow/preferred-fed rats developed binge-like hyperphagia of preferred diet from the second feeder and anticipatory chow hypophagia from the first feeder with a time course suggesting associative learning. The feeding adaptations were dissociable in onset, across individuals, and in their dose-response to the opioid-receptor antagonist nalmefene, suggesting that they represent distinct palatability-motivated processes. Chow/preferred-fed rats showed increased anxiety-like behavior in relation to their propensity to binge as well as increased feed efficiency, body weight, and visceral adiposity. Chow/preferred-fed rats also had increased circulating leptin levels and decreased growth hormone and 'active' ghrelin levels. Thus, the short-term control of food intake in rats with restricted access to highly preferred foods comes to rely more on hedonic, rather than nutritional, properties of food, through associative learning mechanisms. Such rats show changes in ingestive, metabolic, endocrine, and anxiety-related measures, which resemble features of binge eating disorders or obesity.

Neuropsychopharmacology (2008) 33, 524-535; doi:I0.1038/sj.npp. I30 I430; published online I8 April 2007
\end{abstract}

Keywords: binge eating disorder; anticipatory negative contrast; limited access; food intake OR feeding; visceral obesity OR obese; palatability; hedonic evaluation; nalmefene; $\mu$ opioid-receptor or $\kappa$ opioid-receptor antagonist; bulimia OR bulimic; eating disorders; anxiety; ghrelin; leptin; growth hormone; female rats

\section{INTRODUCTION}

Binge eating is abnormal feeding behavior characterized by discrete episodes of rapid, excessive food consumption. Binge episodes, diagnostic features of several eating disorders, typically involve palatable foods rich in sugar and fat and a 'loss of control' (American Psychiatric Association, 2000; Corwin and Buda-Levin, 2004; Yanovski, 2003). Binge eating is more prevalent in obese individuals

\footnotetext{
*Correspondence: Dr P Cottone or Dr EP Zorrilla, Committee on the Neurobiology of Addictive Disorders, SP30-2400, The Scripps Research Institute, 10550 N. Torrey Pines Road, La Jolla, CA 92037, USA, Tel: + I 8587847464 (PC) or + I $85878474 \mid 6$ (EPZ), Fax: + I 858784 7405, E-mail: cottone@scripps.edu (PC) or ezorrilla@scripps.edu (EPZ)

${ }^{4}$ These authors equally contributed to this work.

Received 12 January 2007; revised 2 March 2007; accepted 20 March 2007
}

and, conversely, binge eaters are frequently obese (Pike et al, 2001; Smith et al, 1998). Accordingly, binge eating is a hypothesized etiologic risk factor for obesity (Hudson et al, 2007). A high comorbidity between binge eating and dysphoria has been observed and the causal nature of this relationship remains uncertain (Blazer et al, 1994; Gluck, 2006).

Current binge eating models emphasize a role for dietary restraint in promoting binge behavior (Howard and Porzelius, 1999), with many animal models positing that a history of quantitative food restriction, modeled by limiting the daily caloric ration (eg $66 \%$ of daily intake) (Hagan et al, 2003) or the duration of daily food access (eg $2 \mathrm{~h}$ ) (Inoue et al, 2004), is central to bingeing. However, an alternative conceptualization might emphasize the qualitative aspect of dietary restraint, namely the attempted abstinence of binge eaters from 'forbidden,' palatable foods (Kales, 1990; Knight and Boland, 1989; Fletcher et al, 2007; Mitchell and 
Brunstrom, 2005; Gonzalez and Vitousek, 2004; Stirling and Yeomans 2004; Corwin, 2006; Corwin and Buda-Levin, 2004). Binge eaters restrict their intake of 'forbidden' foods to the point that 'relapse' intake is limited to very brief, often ritualized, binge episodes, perhaps precipitated by mild energy restriction.

Reciprocal to the binge hyperphagia of 'forbidden' foods, the prospect of (predictable experience with) palatable food, leads to refusal of otherwise acceptable alternatives in humans, described by some as finickiness (Pliner et al, 1990). Such a learned change in food acceptance may increase risk for body weight dysregulation and eating disorders because of the increased role placed on sensoryhedonic, rather than nutritional, properties of food for controlling intake (Wardle et al, 2001). Perhaps an analog of this learned change in food acceptance, negative contrast in rodents refers to the hypophagia of an otherwise acceptable tastant that results from having predictably received access to a more preferred substance either immediately before (successive negative contrast) or subsequent to (anticipatory negative contrast) that substance (Flaherty and Checke, 1982; Flaherty and Rowan, 1986; Flaherty et al, 1995). Contrast effects have been studied previously using limitedly available (3-5 $\mathrm{min}$ ) sweet solutions in weight-restricted rats, but have not yet been well-studied vis-à-vis day-to-day food acceptance/intake in subjects' self-determining body weight.

Thus, both binge eating and refusal of less preferred, but perhaps healthier, foods may represent learned behavioral adaptations to contrasting sensory-hedonic experience with food across time. Previously, these phenomena have been segregated to different fields of study and not considered for their possible relatedness. The present study sought to test the hypothesis that rats with highly limited access to preferred food would jointly develop binge-like eating of the preferred diet and anticipatory negative contrast, or hypophagia, of the otherwise acceptable, preceding chow diet. Thus, the main aim of this study was to test the hypothesis that binge eating and anticipatory negative contrast are joint phenomena with shared etiologic roots, as exemplified following intermittent access to palatable food.

A second aim of the study was to test the hypothesis that the preferential $\mu / \kappa$ opioid-receptor antagonist nalmefene would jointly reduce not only binge-like intake of the highly preferred food, but also differentially modulate intake of the less preferred chow according to diet history. Nalmefene was predicted to normalize successive intake of the otherwise differently preferred diets, reducing chow intake in subjects that had not experienced more preferred food options, but increasing intake of less-preferred chow in palatable food-experienced subjects. This novel, second prediction is based on findings that (1) binge-like eating and anticipatory negative contrast are palatability-induced adaptations of eating behavior (Corwin, 2006; Flaherty et al, 1995) and that (2) opioid-receptor antagonists dull palatability-related processes (Cooper, 2004; Yeomans and Gray, 2002).

A third set of descriptive aims was to define the anxietyrelated behavior and metabolic outcomes of intermittent, highly limited access to sugary, palatable diet under the current experimental conditions. To determine whether rats receiving highly limited access to preferred food developed increased anxiety-like behavior, subjects were tested in the elevated plus-maze. To determine whether rats with such a diet history were susceptible to becoming obese, changes in feed efficiency, body weight, adiposity, and circulating leptin, 'active' ghrelin, and growth hormone (GH) levels were measured.

\section{MATERIALS AND METHODS}

\section{Subjects}

Adolescent female Wistar rats $(n=23126-150 \mathrm{~g}$, 41-47 days old; Charles River, Raleigh, NC) were single-housed on arrival in wire-topped, plastic cages $(19 \times 10.5 \times 8$ inches $)$ in a $12: 12 \mathrm{~h}$ lit (reverse cycle, $0800 \mathrm{~h}$ lights off), humidity$(60 \%)$, and temperature-controlled $\left(22^{\circ} \mathrm{C}\right)$ vivarium. Rats had access to corn-based rodent chow (Harlan-Teklad LM485 diet 7012: 65\% (kcal) carbohydrate, $13 \%$ fat, $21 \%$ protein, $3.41 \mathrm{kcal} / \mathrm{g}$; Harlan, Indianapolis, IN) and water ad libitum for 1 week before experiments. Procedures adhered to the National Institutes of Health Guide for the Care and Use of Laboratory Animals (NIH Publication number 8523, revised 1996) and the 'Principles of laboratory animal care' (http://www.nap.edu/readingroom/bookslabrats) and were approved by the Institutional Animal Care and Use Committee of The Scripps Research Institute.

\section{Drug}

Nalmefene hydrochloride, or 17-(cyclopropylmethyl)-4,5 $\alpha$ epoxy-6-methylenemorphinan-3, 14-diol hydrochloride (Mallinckrodt, St Louis, MO) was freshly dissolved in isotonic saline. Nalmefene binds potently to $\kappa\left(K_{\mathrm{i}}=\right.$ $0.083 \mathrm{nM})$ and $\mu\left(K_{\mathrm{i}}=0.24 \mathrm{nM}\right)$ opioid receptor subtypes, but $\sim 2$ orders less potently to $\delta$, than to $\mu$ or $\kappa$, receptors $\left(K_{\mathrm{i}}=16.1 \mathrm{nM}\right)$. Accordingly, nalmefene has high antagonist potency at $\kappa$ and $\mu\left(\mathrm{IC}_{50}=18.5\right.$ and $13 \mathrm{nM}$, respectively $)$, but less so $\delta$, subtypes (Bart et al, 2005; Culpepper-Morgan et al, 1995; Emmerson et al, 1994; Michel et al, 1985).

\section{Diet Preference}

To determine relative diet preference, acclimated rats $(n=8)$ were provided concurrent access to chow diet and to a nutritionally complete, chocolate-flavored, highsucrose $(50 \% \mathrm{kcal})$, AIN-76A-based diet comparable in macronutrient composition and energy density to the chow diet (chocolate-flavored formula PJPPP: 69.1\% (kcal) carbohydrate, $11.8 \%$ fat, $19.1 \%$ protein, metabolizable energy $3.70 \mathrm{kcal} / \mathrm{g}$; formulated as $45-\mathrm{mg}$ precision food pellets to increase its preferredness, Cooper and Francis, 1979; Research Diets Inc., New Brunswick, NJ) (see Table 1). After food intake and preference were stabilized, food preference was calculated as the $\%$ of total 24 -h (kcal) intake consumed in the form of the chocolate-flavored, highsucrose diet, which was found to be strongly preferred by all subjects (see Results) and which hereafter is referred to as 'preferred' diet. 
Table I Diet Composition and Energy Density

\begin{tabular}{|c|c|c|c|c|}
\hline & \multicolumn{2}{|c|}{ Chow } & \multicolumn{2}{|c|}{ Preferred } \\
\hline Manufacturer & \multicolumn{2}{|c|}{ Harlan-Teklad } & \multicolumn{2}{|c|}{ Research diets } \\
\hline Macronutrient composition & $\mathrm{g} \%$ & $\mathrm{kcal} \%$ & $\mathrm{~g} \%$ & kcal\% \\
\hline Protein & 19.9 & 21.0 & 19.8 & 20.6 \\
\hline Carbohydrate & 53.7 & 65.0 & 64.4 & 66.9 \\
\hline kcal/g (metabolizable energy) & \multicolumn{2}{|c|}{3.41} & \multicolumn{2}{|c|}{3.70} \\
\hline
\end{tabular}

Ingredients: Chow: Ground corn, dehulled soybean meal, ground oats, wheat middlings, dehydrated alfalfa meal, soybean oil, corn gluten meal, calcium carbonate,

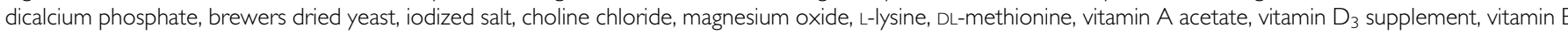
supplement, niacin, calcium pantothenate, riboflavin, thiamine mononitrate, pyridoxine hydrochloride, menadione sodium bisulfite complex (source of vitamin $\mathrm{K}$ activity), folic acid, biotin, vitamin $\mathrm{B}_{12}$ supplement, calcium carbonate, manganous oxide, ferrous sulfate, copper sulfate, zinc oxide, calcium iodate, cobalt carbonate, chromium potassium sulfate, locust bean gum, gelatin, and kaolin. Preferred: Sucrose (fine ground), maltodextrin, casein, corn starch, cellulose, corn oil, mineral mix SI000I, silicon dioxide, vitamin mix VI000I, magnesium stearate, DL-methionine, and choline bitartrate.

Hypothesis 1: Anticipatory negative contrast and binge-like eating develop jointly.

\section{Feeding Procedure}

Baseline. A separate group of subjects $(n=15)$ was acclimated to the following daily testing schedule: $15 \mathrm{~min}$ before dark cycle onset, animals were transferred to a room, weighed, and individually placed in wire mesh cages $(20 \times 25 \times 36 \mathrm{~cm})$. Each test session then consisted of four contiguous periods in the following order: (a) 1-h chow access, (b) 2-h food deprivation, (c) 10-min access to a chow feeder, and (d) 10-min access to a different chow feeder. Rats were then rapidly returned to the home cage and vivarium with chow available ad libitum. During baseline and testing, water was always available ad libitum. White noise $(70 \mathrm{~dB})$ was present in the test room. The 2-h food deprivation sought to (1) make recent intake uniform, (2) increase slightly the motivation to eat, (3) prompt reliable baseline 10 -min intake with subsequent satiation, and (4) help signal the imminent availability of preferred food. Intake was weighed with $0.01 \mathrm{~g}$ precision. Feed efficiency was calculated as body weight gain (mg) per unit (kcal) energy intake. Over $\sim 2$ weeks, intake from the 10min feeders stabilized, with first feeder intake increasing per an associative learning acquisition curve across days (four-parameter logistic regression $r=0.97, p<0.01$ ) (Hartz et al, 2001). This baseline period separated the time course of procedural acquisition/acclimation from that of preferred diet schedule-induced feeding adaptations.

Testing. For testing, rats, matched for body weight, daily food intake, feed efficiency, and food intake within each test session period, were assigned to a 'chow/chow' control group, which received chow access from both 10-min feeders or a 'chow/preferred' group, which also received chow in the first 10 -min feeder, but instead received the preferred diet in the second 10-min feeder. Rats were tested daily until day 52, except when otherwise specified.

Hypothesis 2: Rats with intermittent, highly limited access to sugary, preferred diet will show increased anxiety-like behavior.
Elevated plus-maze. To determine whether rats with highly limited access to the preferred diet developed increased anxiety-like behavior, elevated plus-maze testing was performed under dim illumination as described previously (Zorrilla et al, 2002). The primary measures were the percent of total arm time and entries directed toward the open arms, validated indices of anxiety-related behavior (Fernandes and File, 1996) and the number of closed arm entries, an index of locomotor activity (Cruz et al, 1994). The rats described in hypothesis 1 were tested $3-5 \mathrm{~h}$ into the dark cycle ( $\sim 24-26 \mathrm{~h}$ after prior preferred diet access) on test day 16. The regular feeding session was not performed on this day.

Hypothesis 3: Nalmefene treatment will differentially affect food intake according to diet history.

To determine the role of opioid receptor activity in palatability-induced feeding adaptations, rats received nalmefene $(0,0.01,0.03,0.1,0.3,1 \mathrm{mg} / \mathrm{kg}$, subcutaneously (s.c.)) $20 \mathrm{~min}$ before the first 10 -min feeder. This pretreatment interval was chosen to ensure full antagonist activity throughout the presentation of both feeders. Previous reports indicate that it takes $15-20 \mathrm{~min}$ for the maximum effect of subcutaneous nalmefene to be observed in the rat, with comparable functional activity and ex vivo receptor occupancy maintained for at least $1 \mathrm{~h}$ (June et al, 1998; Unterwald et al, 1997; Landymore et al, 1992). Treatments were given to the rats described in hypothesis 1 using a full Latin square design with 1 to 3 intervening treatment-free test days from days 24 to 37 following three daily acclimating saline injections.

Hypothesis 4: Rats with intermittent, highly limited access to sugary, preferred diet will become obese.

Circulating leptin, GH, and 'active' ghrelin. To determine whether rats with highly limited access to the preferred diet developed endocrine and fat mass changes seen in obesity, rats were overnight fasted $(18 \mathrm{~h})$ and decapitated $2-5 \mathrm{~h}$ into the dark cycle following 53 days on the diet schedules. Rats were killed after a uniform 18 - $\mathrm{h}$ fast to reduce potentially confounding acute feeding effects, including diet historyrelated differences in intake during the experimental feeder 
period or in the home cage. Spanning the rats' inactive cycle, the magnitude of the fast was modest on a caloric basis, comparable with those used previously to study these endocrine factors in rats (Proulx et al, 2005; Drazen et al, 2006) and analogous to the clinical procedure of overnight fasting used to measure these hormones in humans (Falorni et al, 1998; Sherwin et al, 1977). Trunk blood ( $\sim 5 \mathrm{ml})$ was collected in chilled tubes containing $500 \mu \mathrm{l}$ of $0.5 \mathrm{M}$ ethylenediaminetetraacetic acid and $50 \mu \mathrm{l}$ of a commercial protease inhibitor cocktail (Sigma catalog P8340). Plasma was isolated by centrifugation $\left(4^{\circ} \mathrm{C}, 3000 \mathrm{~g}, 15 \mathrm{~min}\right)$ and stored at $-80^{\circ} \mathrm{C}$ until duplicate analysis with immunoassays for rat leptin (LincoPLEX), GH and $\mathrm{Ser}^{3}-n$-octanoylated ghrelin (acyl-ghrelin) enzyme-linked immunosorbent assay (Linco, St Charles, MO). Sensitivity limits were 12, 500, and $33 \mathrm{pg} / \mathrm{ml}$, respectively. Typical intra-assay coefficients of variation are $<5,<4$, and $3.5-5.5 \%$, respectively.

Adiposity. Carcasses were thawed (room temperature) and weighed to determine freezing-related water loss. Gastrointestinal tracts were removed to determine eviscerated weight. Inguinal (subcutaneous) and gonadal (intra-abdominal/visceral) fat pads were dissected, weighed, and returned to the carcass for chemical composition analysis. Total body water, fat mass, and fat-free dry mass (FFDM) were determined using the method of Harris and Martin (1984).

\section{Statistical Analysis}

Changes in test session food intake and cumulative feed efficiency were analyzed using two-way analyses of covariance, with baseline as a covariate. Incremental daily food intake and body weight gain were analyzed using two-way repeated measures analyses of variance (ANOVAs). In both models, diet history was a between-subjects factor and day a within-subjects factor. Student's $t$-test was used to interpret significant group differences and to identify cumulative changes in food intake and body weight gain.

To determine whether the 'acquisition' of binge-like feeding (Hagan and Moss, 1997) and of anticipatory negative contrast (first feeder chow hypophagia) resembled an associative learning process, the following sigmoidal four-parameter logistic regression function was fit to feeder intake (Hartz et al, 2001):

$$
y=\min +\frac{(\max -\min )}{1+10^{\left(\log \mathrm{EC}_{50}-x\right) \text { Hillslope }}}
$$

The min and max parameters model intake before and asymptotic intake after diet history-induced behavioral adaptation ('learning'). The Hillslope describes the rate and valence of intake adaptation. The $\mathrm{EC}_{50}$ describes the number of days that passed until $50 \%$ of maximal behavioral adaptation occurred.

To determine whether rats stably differed in their individual vulnerability to anticipatory negative contrast or binge eating, two-way, random effect intraclass correlations of absolute agreement (Shrout and Fleiss, 1979) were performed on first and second 10-min feeder intakes (kcal) of days 7 to 15 .

Linear regression was used to determine whether rats with limited access to preferred diet showed an altered regularity $\left(r^{2}\right.$, the proportion of variance explained) or nature (slope) of the relation between first and second feeder intake. Regression was also used to test the relation between typical 'binge' magnitude (mean feeder 2 intake from days 7-15) and anxiety-like behavior, as inversely measured by \% open arm entries.

Nalmefene effects on intake were analyzed using two-way repeated measures ANOVAs. Diet history and dose were between- and within-subjects factors, respectively. Linear contrasts determined whether dose effects were log-linearly dependent, and nalmefene's $\mathrm{ED}_{50}$ to reduce second feeder intake (binge-like eating) was estimated using the above sigmoidal dose-response function. Pair-wise dose effects were interpreted using within-subject Dunnett's tests and diet history effects by Student's $t$-tests. Dunnett's test was used to determine whether nalmefene normalized total intake of chow/preferred-fed rats to vehicle-treated chow/ chow-fed levels.

To assess the explanation that hypophagia at the first feeder might reflect a compensatory response to excess weight gain, Pearson correlations were calculated on both cross-sectional and cross-lagged bases for days 7-15. These analyses determined whether an inverse correlation existed between differences in body weight gain on the one hand with concurrent (same day) or subsequent (lagged by 1 or 2 days) differences in first feeder hypophagia (relative to baseline) intake on the other. Correlations were performed on a day-wise basis, averaged following Fisher's $Z$ transformations and backtransformed to obtain an average $r$. Because of the possible instability of day-wise correlations, analyses also were performed correlating the 3-day moving average of body weight gain with the concurrent 3-day moving average of chow hypophagia.

Adiposity, plasma metabolite/hormone levels, and plusmaze measures were analyzed using unpaired or paired Student's $t$-test for between- or within-subjects comparisons, respectively. The software packages were Systat 11.0 (SPSS, Chicago, IL), SigmaPlot 9.0 (Systat Software, Inc., Point Richmond, CA), InStat 3.0 (GraphPad, San Diego, CA), and Prism 3.0 (GraphPad).

\section{RESULTS}

\section{Diet Preference}

The mean $( \pm$ SEM) 24-h intake $(\mathrm{kcal})$ preference ratio for the uniformly preferred chocolate-favored, high-sucrose diet over the chow diet was $92.2 \pm 1.1 \%$ (range: $88.8-97.9 \%$ ).

Hypothesis 1: Anticipatory negative contrast and binge-like eating develop jointly.

\section{Sequential 10-min Feeders}

As predicted, rats receiving highly limited access to preferred diet (chow/preferred) developed hypophagia of chow from the first 10-min feeder (Figure 1a; diet history: $\mathrm{F}(1,12)=14.48, p<0.005$; diet history $\times$ day: $\mathrm{F}(14,168)=$ $2.29, p<0.01)$ and hyperphagia of preferred diet from the second 10-min feeder (Figure 1b; diet history: $\mathrm{F}(1,12)=$ 53.96, $p<0.001$; diet history $\times$ day: $\mathrm{F}(14,168)=8.98$, $p<0.001)$. Feeding adaptations were experience-dependent, as indicated by the diet history $\times$ day interactions and, 
especially by the excellent fits of intake from each feeder to the sigmoidal associative learning function (Figure 1c, Table 2). The two processes had not only different valences, but also different magnitudes and time courses. Acquisition of binge-like intake (feeder 2 intake) exceeded and preceded that of chow hypophagia (feeder 1 intake). Diet history groups differed reliably from one another by day 2 for feeder 2 intake (preferred diet hyperphagia), but not until day 9 for feeder 1 intake (chow hypophagia). The $\mathrm{EC}_{50}$ for binge-like hyperphagia preceded that for 'anticipatory' chow hypophagia by $4-5$ days (Table 2 ).

Although chow/chow-fed rats were almost fully satiated by first feeder intake of $\sim 6 \mathrm{kcal}$, exhibiting little intake ( $\sim 1 \mathrm{kcal}$ ) from the second feeder (Figure 1b), chow/ preferred-fed rats escalated second feeder intake to a max value of $34.4 \mathrm{kcal}$. Thus, $42.9 \pm 2.0 \%$ of their daily intake (or $45.6 \pm 2.7 \%$ of chow/chow daily intake) was consumed within only $10 \mathrm{~min}$ at a rate of one $45 \mathrm{mg}$ food pellet every $2.9 \pm 0.1$ s (range: $151-259$ pellets $/ 10 \mathrm{~min}$ ). Conversely, first feeder chow intake decreased to $3.4 \mathrm{kcal}$ (61\% of baseline first feeder intake).

Body weight gain and first feeder hypophagia. In chow/ preferred rats, greater body weight gain did not concurrently or prospectively predict greater hypophagia at the first feeder from days 7-15, as indicated by a lack of significant day-wise inverse cross-sectional (average $r=0.102$ ) or cross-lagged correlations between these measures (average $r$ 's $=0.022$ and -0.040 for 1 - and 2-day lags, respectively). Similarly, a rat's average weight gain during this period was unrelated to its average magnitude of first feeder hypophagia (average $r=-0.025$ ).

Table 2 Acquisition of Anticipatory Chow Hypophagia and BingeLike Eating in Rats as Modeled by Sigmoidal Regression Analysis

Feeder

First (chow) Second (preferred)

Sigmoidal regression parameter

'Hypophagia' 'Binge-like eating'

\begin{tabular}{lcc}
\hline Min (kcal) & $3.4 \pm 0.3$ & $0.8 \pm 1.7$ \\
Max (kcal) & $5.5 \pm 0.2$ & $34.4 \pm 1.7$ \\
EC $_{50}$ (days) & $7.5 \pm 0.7$ & $3.2 \pm 0.3$ \\
Hillslope (unitless) & $-11.1 \pm 9.5$ & $2.1 \pm 0.4$ \\
Goodness of fit $(r)$ & 0.78 & 0.98 \\
p-value & $<0.001$ & $<0.001$
\end{tabular}

Parameter values (mean \pm SEM, where applicable) from nonlinear fourparameter sigmoidal regression analysis of sequential 10-min feeder intakes of chow/preferred-fed female Wistar rats $(n=8)$ across 15 days of receiving highly limited ( $10 \mathrm{~min}$ ) daily access to a highly preferred chocolate-flavored sugary diet. Following a 2-h food deprivation, rats were daily provided with 10-min access to a first feeder containing chow followed successively by 10 -min access to a second feeder containing the highly palatable diet. The parameters describe the associative acquisition curves of 'anticipatory' hypophagia at the first feeder and binge-like eating at the second feeder that resulted from this diet history. The functions are graphically represented in Figure Ic. See text for further details.
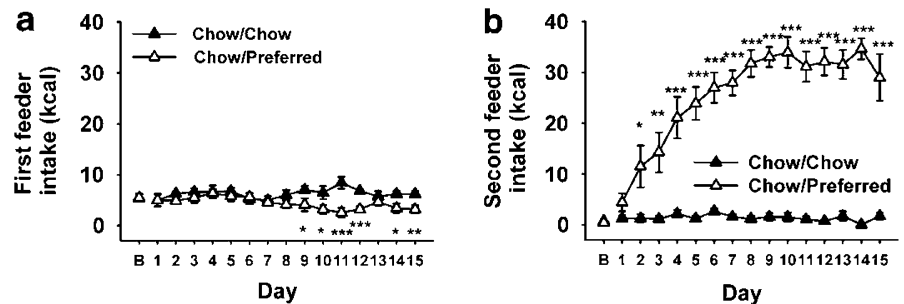

Day

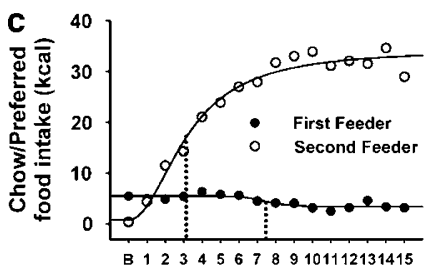

Day

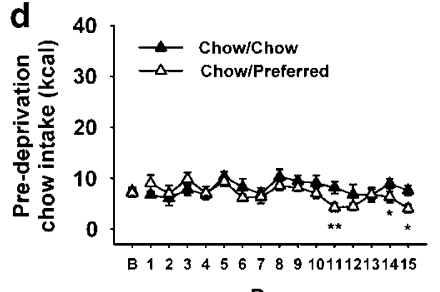

Day

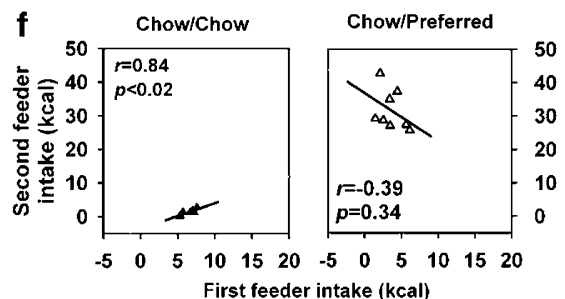

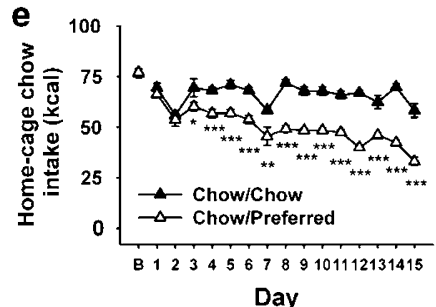

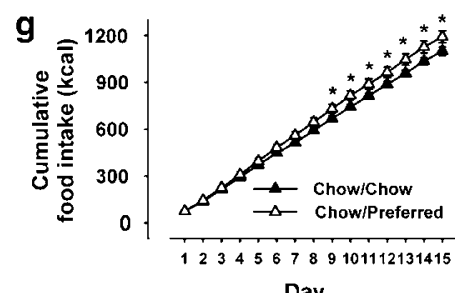

Day

Figure I Effects of daily, I0-min access to a feeder containing a highly preferred diet on food intake, body weight gain, and feed efficiency in female Wistar rats. Following $2 \mathrm{~h}$ of food deprivation, rats were daily provided 10 -min access to a first feeder containing chow followed sequentially by equally brief access to a second feeder containing either chow diet again (chow/chow; $n=7$ ) or a highly preferred, chocolate-flavored sugary diet (chow/preferred; $n=8$ ). Chow was otherwise freely available. Panels represent (mean \pm SEM). (a) First feeder food intake in 10 min. (b) Second feeder food intake in 10 min. (c) Sigmoidal regression of first and second feeder food intake in chow/preferred rats. (d) Predeprivation chow intake in I h. (e) Home-cage chow intake in $20 \mathrm{~h}$ and $40 \mathrm{~min}$. (f) Linear regression of first feeder intake ( $x$-axis) vs second feeder intake ( $y$-axis). Values represent the averaged intakes from test days $7-15$. ( $g$ ) Cumulative food intake. *Differs from chow/chow $p<0.05$, *** $p<0.0$ I, **** $p<0.00$ I (Student's $t$-test). 
Individual difference and correlation analysis. Unlike the lack of relation of body weight gain to first feeder hypophagia, intraclass correlation analysis showed strong, stable individual differences in intake of chow/preferred-fed rats from both the first $\left(I C C[2,9]=0.86, r^{2}=0.74 ; \mathrm{F}(7,56)=\right.$ 7.93, $p<0.00001)$ and second feeder $\left(\right.$ ICC $[2,9]=0.89, r^{2}=$ $0.79 ; \mathrm{F}(7,56)=9.42, p<0.00001)$. In contrast, chow/chowfed rats showed no individual differences in first feeder intake $\left(I C C[2,9]=0.37, r^{2}=0.14 ; \mathrm{F}(6,48)=1.61, p=0.17\right)$ and smaller individual differences in second feeder intake $\left(I C C[2,9]=0.64, r^{2}=0.41 ; \mathrm{F}(6,48)=2.78, p<0.05\right)$. Thus, after mild deprivation, chow/chow-fed rats refed in a manner relatively independent of individual-specific characteristics. In contrast, chow/preferred-fed rats showed trait-like, individual-specific magnitudes of 'anticipatory' chow hypophagia and preferred diet hyperphagia following mild energy restriction.

Although intake of individual chow/chow-fed rats was highly and positively correlated across feeders (slope $=0.78$, reliably greater than $0, \mathrm{~F}(1,5)=11.67, p<0.02)$, consistent with sustained refeeding, there was no reliable correlation between the intake of individual chow/preferred-fed rats from the chow to preferred diet feeder (slope indistinguishable from $0, \mathrm{~F}(1,6)=1.07, p=0.34$ ) (see Figure 1f, difference in $\left.r^{2}, z=2.43, p=0.01\right]$ ). Thus, intakes of individual chow/ preferred-fed rats did not exhibit positive or inverse 'energy homeostatic/compensatory' short-term correlations across diets/feeders. Those subjects that showed the strongest anticipatory chow hypophagia were not necessarily those that showed the greatest binge-like hyperphagia.

Predeprivation 1-h chow intake. Predeprivation 1-h chow intake of chow/preferred-fed rats was also significantly suppressed starting from test day 11 (Figure 1d; diet history $\times$ day interaction $\mathrm{F}(14,182)=2.35, p<0.01)$. However, the decrease in predeprivation 1-h chow intake was later in onset (day $11 v s$ day 9) and significantly smaller both on an absolute $(t(7)=-5.59, p<0.001)$ and proportional basis $(t(7)=-3.00, p<0.01)$ than the average reduction of first feeder intake observed in chow/preferred-fed rats. Importantly, these findings are consistent with an 'anticipatory' interpretation of first feeder hypophagia and, like the absence of correlations with body weight gain, inconsistent with the alternative interpretation that first feeder hypophagia resulted from residual energy homeostatic responses to prior binge feeding or excess weight gain.

Home-cage chow intake. Home-cage chow intake of chow/ preferred-fed rats progressively decreased in an experiencedependent manner (Figure 1e; diet history: $\mathrm{F}(1,12)=100.64$, $p<0.001$; diet history $\times$ day: $\mathrm{F}(14,168)=12.06, p<0.001)$, significantly so by day 3 of testing.

Total daily intake. Despite the substantial changes in intake of particular diets within the day, ANOVA did not reveal significant effects of diet history or diet history $\times$ day on incremental total daily energy intake. However, Student's $t$-tests showed that cumulative energy intake of chow/preferred-fed rats slightly, but significantly, exceeded that of chow/chow-fed rats beginning from test day 9 (Figure 1g).
Hypothesis 2: Rats with intermittent, highly limited access to sugary, preferred diet will show increased anxiety-like behavior.

Chow/preferred-fed rats showed significantly decreased relative time spent within (Figure 2a, left) and entries into $($ mean \pm SEM: $\quad 21.5 \pm 4.6$ vs $34.7 \pm 4.7 \% ; \quad t(13)=2.14$, $p<0.05)$ the open arms of the elevated plus-maze as compared with chow/chow-fed rats, an anxiogenic-like effect. The number of closed arm entries, a control measure of locomotor activity (Cruz et al, 1994), was unchanged by diet history (Figure 2a, right). A rat's typical 'binge' size strongly correlated with its degree of anxiety-like behavior, indicated in a substantial inverse correlation between average feeder 2 intake and \% open arm time in chow/ preferred-fed rats (Figure $2 \mathrm{~b}$ ). This relationship accounted for most of the variance in these measures $(77.4 \%)$ and was not significant in regression analysis of chow/chow-fed rats regardless of whether an outlier was included $(36.5 \%)$ or excluded (9.2\%).

Hypothesis 3: Nalmefene treatment will differentially affect food intake according to diet history.

Under vehicle-treated conditions, chow/preferred-fed rats showed 'anticipatory' chow hypophagia (feeder 1) and preferred diet hyperphagia (feeder 2) (Figure 3). As predicted, nalmefene treatment differentially affected 10 min chow intake from the first feeder according to diet history (diet history $\times$ dose: $\mathrm{F}(5,65)=3.60, p<0.01$; dose: $\mathrm{F}(5,65)=3.06, p<0.05)$. Specifically, nalmefene decreased intake of chow/chow-fed rats in a log-linear, dose-dependent fashion $(\mathrm{F}(1,30)=13.35, p<0.001)$, with significant pair-wise reductions from vehicle observed at the 0.03 and $1 \mathrm{mg} / \mathrm{kg}$ doses. In contrast, nalmefene significantly increased chow intake of chow/preferred-fed rats at the $0.03 \mathrm{mg} / \mathrm{kg}$ dose (Figure 3, left). Consequently, low-dose nalmefene pretreatment (s.c., $0.03 \mathrm{mg} / \mathrm{kg}$ ) blocked 'anticipatory' chow hypophagia.
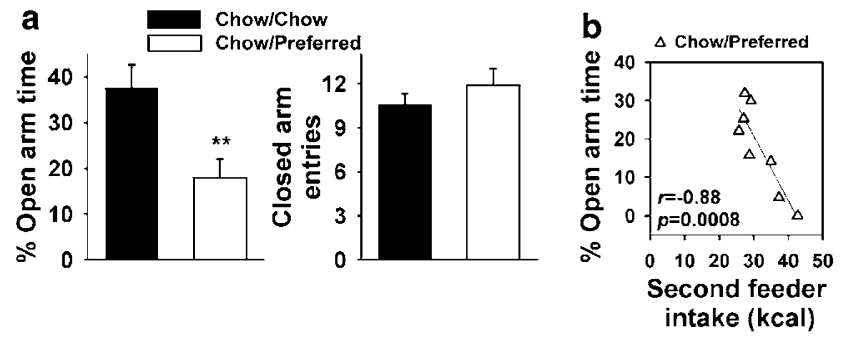

Figure 2 Effects of daily, 10-min access to a feeder containing a highly preferred diet on elevated plus-maze behavior in female Wistar rats. Following $2 \mathrm{~h}$ of food deprivation, rats were daily provided 10 -min access to a first feeder containing chow followed sequentially by equally brief access to a second feeder containing either chow diet again (chow/chow; $n=7$ ) or a highly preferred, chocolate-flavored sugary diet (chow/ preferred; $n=8$ ). Chow was otherwise freely available. Panels represent mean \pm SEM. (a) Elevated plus-maze behavior reflecting (left) anxiety-like behavior, as indicated by the percent of total arm time directed towards the open arms (less \% open arm time signifies more anxiogenic-like behavior), and (right) locomotor activity, as indicated by the number of closed arm entries. Rats were tested 3-5 h into the dark cycle ( 24-26 h after their last preferred diet access) after 16 test days (Student's $t$-tests). (b) Linear regression of second feeder intake ( $x$-axis) vs \% open arm time (y-axis). Values represent the averaged intakes from test days 7-15.

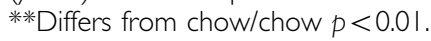



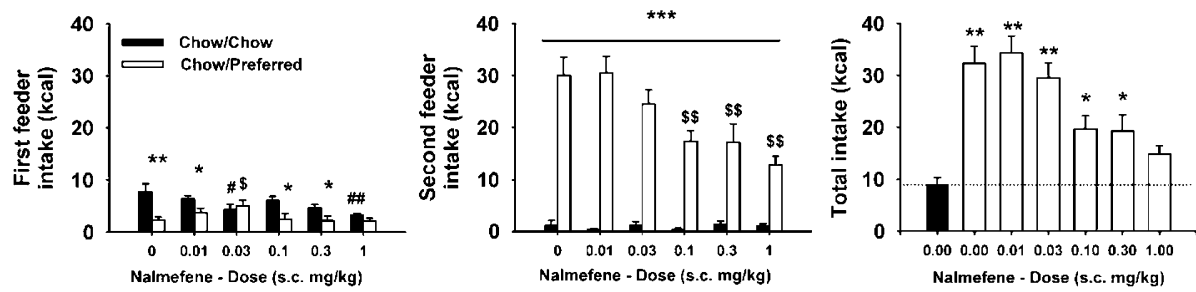

Figure 3 Effects of daily, I0-min access to a feeder containing a highly preferred diet on feeding responses to nalmefene, a $\mu / \kappa$ opioid-receptor antagonist in female Wistar rats. Following $2 \mathrm{~h}$ of food deprivation, rats were daily provided I0-min access to a first feeder containing chow followed sequentially by equally brief access to a second feeder containing either chow diet again (chow/chow; $n=7$ ) or a highly preferred, chocolate-flavored sugary diet (chow/ preferred; $n=8$ ). Chow was otherwise freely available. Panels represent mean \pm SEM. Effects of pretreatment (20 min before first feeder) with nalmefene $(0,0.01,0.03,0.1,0.3,1 \mathrm{mg} / \mathrm{kg}$, s.c.) on (left) first feeder food intake in $10 \mathrm{~min}$, (middle) second feeder food intake in $10 \mathrm{~min}$, and (right) total 20-min food intake (Dunnett's tests). *Differs from chow/chow $p<0.05$, ${ }^{*} p<<0.01$, **** $<0.001$, ${ }^{\#}$ differ from chow/chow vehicle condition $p<0.05,{ }^{\# \#} p<0.01$, ${ }^{\$}$ differs from chow/preferred vehicle condition $p<0.05,{ }^{\$ \$} p<0.01$.

Nalmefene also differentially suppressed intake from the second feeder according to diet history (diet history $\times$ dose: $\mathrm{F}(5,65)=6.60, p<0.001$; dose: $\mathrm{F}(5,65)=6.28, p<0.001)$. Specifically, nalmefene potently $\left(\mathrm{ED}_{50}=0.025 \mathrm{mg} / \mathrm{kg}\right.$, $\left.r^{2}=0.97\right)$ and substantially reduced intake of the preferred diet by chow/preferred-fed rats in log-linear, dose-dependent fashion $(\mathrm{F}(1,30)=35.37, p<0.0001)$, without reliably altering chow intake of chow/chow-fed rats (Figure 3, middle).

Consistent with these findings, nalmefene treatment also differentially reduced total 20-min intake of the two groups, indicated by overall $(\mathrm{F}(5,65)=5.31, p<0.0001)$ and log-linear contrast $(\mathrm{F}(1,13)=44.68, \quad p<0.0001)$ diet history $\times$ dose interaction effects. Nalmefene more efficaciously reduced intake of chow/preferred and chow/chow rats (log-linear: slope: $-4.05 \pm 0.94$ vs $-0.69 \pm 0.32 \mathrm{kcal} /$ dose increment, respectively). Nalmefene also more potently reduced total 20 -min intake in chow/preferred rats (dose: $\mathrm{F}(5,35)=8.48$, $p<0.0001$ ), reducing intake significantly at $0.1,0.3$, and $1 \mathrm{mg} /$ $\mathrm{kg}$ doses, whereas only the highest dose $(1 \mathrm{mg} / \mathrm{kg})$ was effective in chow/chow rats (dose: $\mathrm{F}(5,30)=2.70, p<0.05$ ). Overall, the highest nalmefene dose $(1 \mathrm{mg} / \mathrm{kg})$ reduced total 20-min intake of chow/preferred-fed rats to a level that no longer reliably exceeded that of vehicle-treated chow/chowfed controls (Figure 3, right). Nalmefene treatment did not exhibit carryover effects on first or second feeder intake of intervening post-treatment days.

Hypothesis 4: Rats with intermittent, highly limited access to sugary, preferred diet will become obese.

Body-weight gain and feed efficiency. Chow/preferred-fed rats gained more body weight than chow/chow-fed rats (diet history: $\mathrm{F}(1,13)=10.79, \quad p<0.01 ; \quad$ diet history $\times$ day: $\mathrm{F}(14,182)=5.96, p<0.001)$. Significant group differences were evident by day 5 (4 days before differences in cumulative energy intake), increasing through day 15 (Figure 4a). By day 15, chow/preferred-fed rats had gained $14.3 \mathrm{~g}$ more than chow/chow-fed rats despite having only ingested $92 \mathrm{kcal}$ more and received only $2.5 \mathrm{~h}$ access to the sugary diet. This weight gain in excess of energy intake reflected an increase in cumulative feed efficiency (Figure $4 \mathrm{~b}$ ), which differed significantly per diet history $(\mathrm{F}(1,12)=10.14, p<0.01)$ by day 5 . By day 24 , chow/ preferred-fed rats weighed more on an absolute basis than chow/chow-fed rats (Figure 5a), and were $11 \%$ heavier by
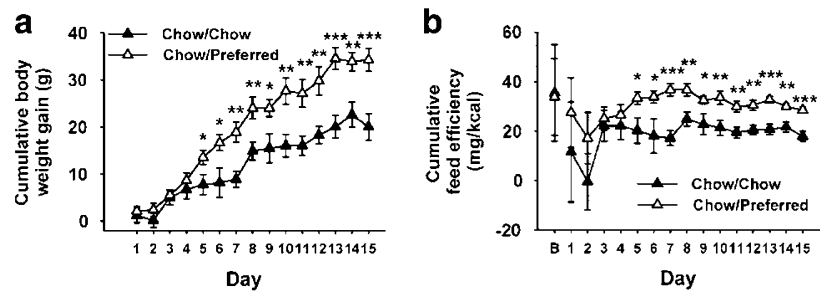

Figure 4 Effects of daily, 10-min access to a feeder containing a highly preferred diet on cumulative body weight and cumulative feed efficiency in female Wistar rats. Following $2 \mathrm{~h}$ of food deprivation, rats were daily provided 10-min access to a first feeder containing chow followed sequentially by equally brief access to a second feeder containing either chow diet again (chow/chow; $n=7$ ) or a highly preferred, chocolateflavored sugary diet (chow/preferred; $n=8$ ). Chow was otherwise freely available. Panels represent (mean \pm SEM). (a) Cumulative body weight gain. (b) Cumulative feed efficiency. *Differs from chow/chow $p<0.05$, *** $p<0.0$ I, **** $p<0.00$ I (Student's $t$-test).

day 53 (despite having only received $\sim 9 \mathrm{~h}$ total access to the preferred diet).

Adiposity and endocrine status. Excess body weight was largely because of a $57 \%$ increase in fat mass (Figure $5 b$, left). Accordingly, chow/preferred-fed rats were fattier, as defined by a significant increase in \% body fat, with no change in the proportion of body weight accounted for by FFDM (Figure 5b, left) and a reduced \% water mass (mean \pm SEM: $71.9 \pm 0.8$ vs $74.3 \pm 0.7 \%, p<0.05$ ). Fat pad analysis showed significant expansion of subcutaneous (inguinal; $41 \%$ increase) and, especially, visceral (gonadal; $76 \%$ increase) fat depots (Figure 5, right).

In plasma, chow/preferred-fed rats also showed $60 \%$ higher leptin-immunoreactivity, 47\% lower GH-immunoreactivity, and 59\% lower acylated ghrelin-immunoreactivity, as compared with chow/chow-fed rats (Figure 6a-c). As expected, plasma leptin-immunoreactivity correlated strongly with total fat mass within $(r s=0.82$ and 0.86 for chow/preferred- and chow/chow-fed groups, $p s<0.05)$ and across groups $(r=0.91, p<0.001)$ (Figure $6 \mathrm{~d}$ ) as well as with gonadal $(r=0.85, p<0.001)$ and inguinal fat pad masses $(r=0.78, p<0.01)$.

\section{DISCUSSION}

Female rats with highly restricted access to a highly preferred, high sucrose diet developed experience-depen- 

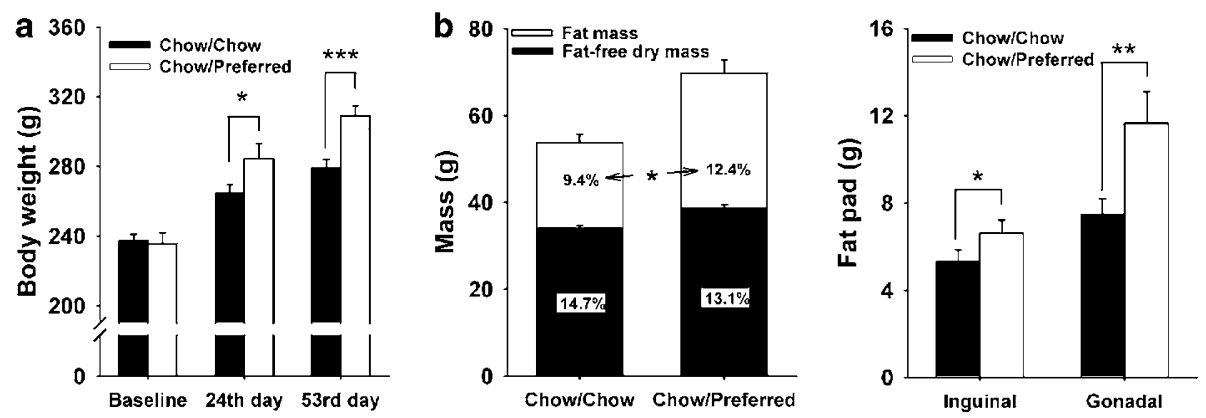

Figure 5 Long-term effects of daily, 10-min access to a feeder containing a highly preferred diet in female Wistar rats. Following $2 \mathrm{~h}$ of food deprivation, rats were daily provided 10 -min access to a first feeder containing chow followed sequentially by equally brief access to a second feeder containing either chow diet again (chow/chow; $n=7$ ) or a highly preferred, chocolate-flavored sugary diet (chow/preferred; $n=8$ ). Chow was otherwise freely available. Panels show mean \pm SEM. (a) Body weight. (b) Adiposity. (Left) Absolute (bars) and proportional (embedded numerals) fat mass and FFDM and (right) inguinal (subcutaneous) and gonadal (visceral) fat pad weights. *Differs from chow/chow $p<0.05, * * 0<0.01$, **** $p<0.00$ l (Student's t-test).

a
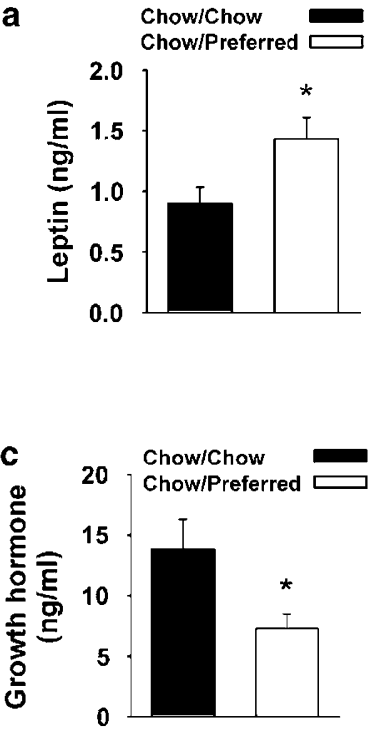
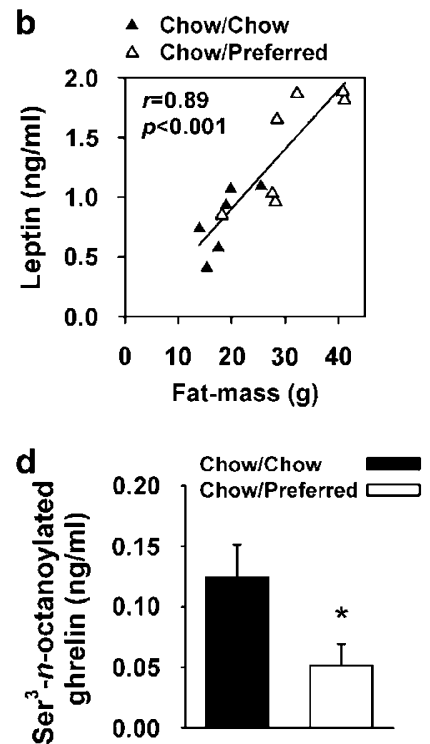

Figure 6 Long-term effects of daily, I0-min access to a feeder containing a highly preferred diet in female Wistar rats. Following $2 \mathrm{~h}$ of food deprivation, rats were daily provided 10 -min access to a first feeder containing chow followed sequentially by equally brief access to a second feeder containing either chow diet again (chow/chow; $n=7$ ) or a highly preferred, chocolateflavored sugary diet (chow/preferred; $n=8$ ). Chow was otherwise freely available. Panels show mean +SEM. (a) Plasma levels of leptin immunoreactivity and (b) correlation of leptin with total fat mass. (c) Plasma levels of $\mathrm{GH}$-immunoreactivity and (d) $\mathrm{Ser}^{3}$-n-octanoylated ghrelin-immunoreactivity. *Differs from chow/chow $p<0.05$ (Student's t-test).

dent, binge-like hyperphagia of the diet and anticipatory hypophagia of a less preferred alternative. The adaptations in feeding behavior were dissociable from one another in time, across individuals, and in their pharmacological doseresponse to an opioid-receptor antagonist, suggesting that they represent distinct palatability-motivated processes with shared etiologies. Rats with restricted access to the highly preferred food also spontaneously showed increased anxiety-like behavior and rapidly became viscerally obese.

Binge-like eating developed quickly $\left(\mathrm{EC}_{50}=3.2\right.$ days $)$ per logistic growth function, consistent with a learned, associative adaptation (Hartz et al, 2001). 'Binges' were substantial, accounting for almost half of daily caloric intake and were $\sim 7$-fold greater than the caloric intake that was able to

satiate chow-maintained control rats exposed to the same brief $(2 \mathrm{~h})$ restriction period. During the first 8 days of testing (when anticipatory chow hypophagia had not yet developed), 'binges' occurred even though rats had just eaten otherwise satiating quantities of the chow from the first feeder. On subsequent days, the degree of anticipatory chow hypophagia never approach the degree of overeating. 'Binges' were attenuated dose-dependently by very low doses of nalmefene (relative to those often used in the literature), a preferential $\mu / \kappa$ opioid-receptor antagonist which blunts binge ethanol drinking by alcoholics (Mason et al, 1994, 1999) and which lowers the consumption and subjective 'pleasantness' of palatable food in humans (Yeomans et al, 1990; Yeomans and Gray, 2002; Yeomans and Wright, 1991). Rats ate very quickly within binges ( $\sim 2.9 \mathrm{~s} / 45 \mathrm{mg}$ pellet without discounting non-eating time), faster than rats maintained ad libitum on the same preferred diet (unpublished observations). The findings collectively suggest a hedonic component to the binge-like feeding adaptations. Interestingly, the propensity to develop binge-like eating was a highly stable, individual-specific trait, with the subject's identity accounting for $79.7 \%$ of the variance in the typical size of acquired 'binge' episodes.

Although binge-like eating developed for the restricted, preferred diet, chow/preferred-fed rats decreased their intake of less-preferred chow in their home-cages and also in the predeprivation and postdeprivation ('first feeder') portions of the test session. The onset of these hypophagias differed, with chow hypophagia in the home-cage (day 3 ) preceding those from the first feeder (day 9) and predeprivation (day 11) test periods by about 1 week. Studies were not designed to distinguish the mechanisms responsible for reductions in home-cage or predeprivation chow intake. However, several findings support the interpretation that chow hypophagia at the first feeder was a form of anticipatory negative contrast (Flaherty and Checke, 1982; Flaherty and Rowan, 1986; Flaherty et al, 1995) and not energy homeostatic compensation for accruing weight gain, lasting satiety, or successive negative contrast. First, there was no concurrent or prospective relation between differences in weight gain and the magnitude of chow hypophagia (unlike strong individual differences seen in chow hypophagia). Second, first feeder chow hypophagia began 2 days earlier and was greater in magnitude than hypophagia during the earlier predeprivation hour. An energy homeostatic 
explanation would predict similar onset and magnitude (if not faster onset and greater magnitude) of anorexia during the earlier predeprivation hour, if compensatory hypophagia was ostensibly sustained through the subsequent first feeder presentation. Third, there was no inverse correlation between the degree of first feeder chow hypophagia and the magnitude of second feeder binges. Fourth, first feeder hypophagia $\left(\mathrm{EC}_{50}=7.5\right.$ days) developed $\sim 4-5$ days after binge-like eating. Consistent with the present results, anticipatory negative contrast for an otherwise acceptable sweet solution occurs independent of body weight or caloric intake changes, when the solution is historically succeeded by a more preferred saccharin solution (Flaherty and Rowan, 1986). Still, a possible contribution of energy homeostatic mechanisms in altering the reward threshold for food acceptance in the present study cannot be excluded. For example, levels of leptin and ghrelin, appetite-regulatory homeostatic hormones that directly modulate reward neurocircuitry (Hommel et al, 2006; Abizaid et al, 2006; Hao et al, 2006; Shizgal et al, 2001) differed as a result of diet history and perhaps changed before onset of body weight differences. Longitudinal analysis of leptin and ghrelin levels or pharmacological manipulation of their action could help clarify any contribution of these energy homeostatic regulatory hormones to anticipatory chow hypophagia in the present study.

As with bingeing, individual rats also stably differed in the degree to which they developed anticipatory negative contrast, with identity accounting for $74.3 \%$ of the variance in first feeder intake. Importantly, however, this trait was statistically unrelated to and later developing than binge-like eating. Also, whereas nalmefene log-linearly and monophasically reduced binge-like eating with an $\mathrm{ED}_{50}$ of $0.025 \mathrm{mg} / \mathrm{kg}$ and near normalization of total food intake at the $1 \mathrm{mg} / \mathrm{kg}$ dose, the opioid antagonist blocked anticipatory negative contrast only at a single intermediate dose $(0.03 \mathrm{mg} / \mathrm{kg})$.

Anticipatory chow hypophagia from the first feeder developed per a sigmoidal logistic growth function, consistent with a learned, associative process (Hartz et al, 2001). This evidence for an associative, learned adaptation is inconsistent with several potential alternative explanations, including that there was no adaptation across time, that learning was non-associative in nature (eg sensitization or habituation to the diets or test environments) or several non-learned adaptations (eg change in stomach size, nonPavlovian change in energy homeostatic hormone action). Several cues might have served as conditioned stimuli predictive of imminent preferred food availability, including the experimenter, test environment, deprivation period, or even the preceding first feeder (chow) presentation. Indeed, hyperphagia was significantly reduced $(10.9 \mathrm{kcal}$, or $34 \%$, less, $p<0.001$ ) if the first feeder was not presented, consistent with an acquired role for this stimulus in preparing or facilitating preferred food intake (data not shown). Manipulating such conditioned stimuli will be useful for distinguishing between unconditioned and conditioned components of preferred food hyperphagia and their neurochemical substrates.

That nalmefene, a $\mu / \kappa$ opioid-receptor antagonist, differentially reduced binge-like preferred food hyperphagia is consistent with previous reports that the endogenous opioid system subserves the control of hedonic, rather than nutritionally, motivated intake in both humans and animals
(Olszewski and Levine, 2007). Several previous findings support the hypothesis that mesolimbic opioid receptors modulate behavioral responses to rewarding stimuli, including hedonically driven consumption of preferred foods (Kelley et al, 2002). Nalmefene may have blunted binge-like eating by blocking opioid receptors in the ventral tegmental area, thereby disinhibiting GABAergic inhibitory interneurons that synapse on dopamine neurons and decreasing dopamine release in the shell of the nucleus accumbens (Taber et al, 1998; MacDonald et al, 2003, 2004). Nalmefene also might have acted by blocking $\mu$-opioid receptors in the nucleus accumbens shell or ventral pallidum (Woolley et al, 2006; Ward et al, 2006), cooperative components of a neurocircuit for amplifying appetitive responses to preferred foods, substances of abuse, and other rewards (Smith and Berridge, 2007; Kelley et al, 2005).

Anticipatory negative contrast has been interpreted alternatively as: devaluation (whereby the hedonic value of the first tastant is decreased as a result of historical or representational comparisons to a more preferred tastant), inhibition (whereby rats learn that a more preferred tastant is imminent and correspondingly inhibit intake of a less preferred, predictive, tastant), or behavioral competition (whereby conditioned anticipatory behavior interferes with ingestion of the first tastant) (Flaherty et al, 1995). Although the present data do not clearly differentiate between these interpretations, they suggest a hedonic, non-energy homeostatic account of anticipatory negative contrast. First, anticipatory chow hypophagia occurred despite the preceding $2 \mathrm{~h}$ of food deprivation, after which one might expect animals to accept energy-containing food. This finding is consistent with observations that food deprivation paradoxically increases sensitivity to palatability (Hunt et al, 1988; Kauffman et al, 1995).

Second, a single low dose of nalmefene $(0.03 \mathrm{mg} / \mathrm{kg})$ blocked anticipatory chow hypophagia by increasing acceptance of the less preferred chow, whereas nalmefene monophasically decreased chow intake of rats that had never experienced the preferred diet. The differential actions of nalmefene on chow intake according to diet history support the hypothesis that opioids also participate in learned associative, appetitive processes that underlie food acceptance and selection (Barbano and Cador, 2006; Jarosz et al, 2006; Kas et al, 2004). This conclusion differs from prevailing views that opioid-receptor antagonists simply are anorectic per se (especially for palatable food) or modulate putative 'intrinsic' hedonic properties of foods (Cooper, 2004; de Zwaan and Mitchell, 1992).

Rats that received highly limited access to the sugary, highly preferred diet spontaneously showed increased anxiety-like behavior 1 day after their most recent access to preferred food. A rat's typical binge size was strongly correlated with its subsequent degree of anxiety-like behavior. Whether anxiogenic-like behavior was due to the long-term diet history or acute withdrawal (Cooper, 2004) from the preferred diet is unclear. Scheduled food access per se and recent hypophagia are unlikely to account for the increased anxiety-like behavior because scheduled food deprivation increased relative open arm exploration in the elevated plus-maze, an anxiolytic-like effect (Inoue et al, 2004). Similarly, obesity is unlikely to account for the increased anxiety-like behavior because Zucker lean and 
obese rats do not differ in plus-maze behavior (Chaouloff, 1994) and because selectively bred diet-induced obese and diet-induced resistant rats do not spontaneously differ in open field emotionality (Levin et al, 2000). An important question for future study is whether the anxiety-like behavior shown by chow/preferred-fed rats results from receiving the preferred diet per se, as opposed to the highly limited or intermittent nature of access. Overall though, the results show that rats with highly restricted access to a preferred food showed not only binge-like eating, but also correspondingly greater behavioral anxiety, findings consistent with the comorbidity of binge-eating disorders and obesity on the one hand with pathological anxiety on the other (Gluck, 2006; Kessler et al, 1994; Specker et al, 1994).

Rats with limited access to the preferred diet gained body weight and fat disproportionate to the total amount of energy consumed, findings which cannot be accounted for by the total duration of access they received to the preferred diet $(\sim 9 \mathrm{~h})$. Diets had similar fat, protein, and carbohydrate proportions, so differences in macronutrient composition do not explain the effects. Despite only consuming $8.3 \%$ more energy, rats with highly limited access to the preferred diet gained $71.3 \%$ more body weight over 15 days. By the end of the study, chow/preferred-fed rats had gained $88 \%$ more body weight, owing to preferential accretion of visceral body fat, which increases the risk for cardiovascular disease and metabolic disease (Despres, 1993; Wajchenberg, 2000). The greater feed efficiency of chow/preferred-fed rats may result from the sucrose content of the preferred diet (Kanarek et al, 1987; Kanarek and Orthen-Gambill, 1982) as well as the acquired habit of consuming large energy loads following self-imposed periods of relative hypophagia (Batista et al, 1997). This self-determined 'meal-fed'-like pattern of sustained dietary restraint interrupted predictably by a single large meal/binge models eating patterns of some dieters and patients with eating disorders and, via greater prandial insulin responses (Calderon et al, 2004; Taylor et al, 1999), may promote lipogenesis.

Rats that received highly limited access to the preferred diet also developed endocrine changes seen in human obesity, including increased circulating leptin (Considine et al, 1996) and decreased circulating $\mathrm{Ser}^{3}-n$-octanoylated ghrelin levels. Leptin, the $o b$ gene product, is a $16-\mathrm{kDa}$, primarily white adipose tissue-derived circulating hormone (Bates and Myers, 2003; Guha et al, 2003; Pico et al, 2003) that acts as a lipostatic negative feedback signal to regulate energy balance. With increasing fat stores, circulating leptin levels increase to curb appetite and facilitate energy utilization (Bates and Myers, 2003). Accordingly, in the present study, leptin levels increased and correlated strongly with accrued total fat mass (Considine et al, 1996; Maffei et al, 1995). Unlike leptin, ghrelin, a 28residue, post-translationally acylated, endogenous ligand of the GH secretagogue receptor (GHSR1a), is a predominantly stomach-derived, anabolic hormone whose circulating levels are homeostatically increased by energy insufficiency to signal the central nervous system. Given pharmacologically, the $\mathrm{Ser}^{3}-$ $n$-octanoylated form of ghrelin is orexigenic and decreases energy expenditure and utilization of fat as an energy substrate, leading to weight gain and adiposity with chronic central administration (Druce et al, 2006; Tschop et al, 2000; Wortley et al, 2005). Because leptin and ghrelin respectively increased and decreased in chow/preferred-fed rats, obesity and feeding adaptations probably developed despite energy balance-appropriate, homeostatic accommodations to levels of both hormones (similar to diet-induced human obesity), rather than because of dysregulated release.

Human obesity also has been associated with decreased serum GH concentrations, reflecting reduced half-life, frequency of secretory episodes, and daily production (Scacchi et al, 1999). Chow/preferred-fed rats similarly showed $47 \%$ reductions in circulating $\mathrm{GH}$. Of potential pathophysiologic relevance, conditions with decreased GH levels (eg aging, GH deficiency syndrome, and obesity) carry increased risk for cardiovascular disease (Gola et al, 2005; Hoffman, 2005).

In sum, rats with highly limited access to a high-sucrose, highly preferred diet jointly developed binge-like eating and anticipatory negative contrast, a possible determinant of food acceptability, in female Wistar rats. These learned, palatability-motivated feeding adaptations were opioiddependent and dissociable in time and individual from one another. A single low dose of nalmefene blocked anticipatory negative contrast and potently and progressively reduced 'bingeing,' almost normalizing total caloric intake. Rats with highly limited access to a sugary preferred diet showed increased anxiety-like behavior and morphometric and hormonal signs of visceral obesity. The results support the hypothesis that highly restricted access to 'forbidden' palatable foods may have an etiologic role in the development of binge eating, food preferences, obesity, and associated disorders.

\section{ACKNOWLEDGEMENTS}

This work was supported by grants from the National Institute of Diabetes and Digestive and Kidney Diseases (DK64871, DK77616 and the University of Alabama at Birmingham Small Animal Phenotyping Core (P30DK56336, P30NS057098)). We thank Tim Nagy and the NIDDK Program Project-funded University of Alabama-Birmingham Clinical Nutrition Research Unit Small Animal Phenotyping Core for the body composition analysis. We thank Mike Arends for editorial assistance, Bob Lintz for technical assistance, and Drs Mark Azar, Brendan Walker and three anonymous reviewers for scholarly contributions. Nalmefene hydrochloride was kindly provided by Mallinckrodt (Mallinckrodt, St Louis, MO). This is manuscript number 18572 from The Scripps Research Institute.

\section{DISCLOSURE/CONFLICT OF INTEREST}

The authors declare no conflicts of interest.

\section{REFERENCES}

Abizaid A, Liu ZW, Andrews ZB, Shanabrough M, Borok E, Elsworth JD et al (2006). Ghrelin modulates the activity and synaptic input organization of midbrain dopamine neurons while promoting appetite. J Clin Invest 116: 3229-3239.

American Psychiatric Association (2000). Diagnostic and Statistical Manual of Mental Disorders (4th edn) text revision. American Psychiatric Press: Washington, DC.

Barbano MF, Cador M (2006). Differential regulation of the consummatory, motivational and anticipatory aspects of feeding behavior by dopaminergic and opioidergic drugs. Neuropsychopharmacology 31: 1371-1381. 
Bart G, Schluger JH, Borg L, Ho A, Bidlack JM, Kreek MJ (2005). Nalmefene induced elevation in serum prolactin in normal human volunteers: partial kappa opioid agonist activity? Neuropsychopharmacology 30: 2254-2262.

Bates SH, Myers MG (2003). The role of leptin receptor signaling in feeding and neuroendocrine function. Trends Endocrinol Metab 14: 447-452.

Batista MR, Ferraz M, Bazotte RB (1997). Are physiological changes in meal-fed rats determined by the amount of food ingested in the last meal or due to feeding schedule? Physiol Behav 62: 249-253.

Blazer DG, Kessler RC, McGonagle KA, Swartz MS (1994). The prevalence and distribution of major depression in a national community sample: the National Comorbidity Survey. Am J Psychiatry 151: 979-986.

Calderon LL, Yu CK, Jambazian P (2004). Dieting practices in high school students. J Am Diet Assoc 104: 1369-1374.

Chaouloff F (1994). Failure to find behavioural differences between lean and obese Zucker rats exposed to novel environments. Int J Obes Relat Metab Disord 18: 780-782.

Considine RV, Sinha MK, Heiman ML, Kriauciunas A, Stephens TW, Nyce MR et al (1996). Serum immunoreactive-leptin concentrations in normal-weight and obese humans. $N$ Engl J Med 334: 292-295.

Cooper SJ (2004). Endocannabinoids and food consumption: comparisons with benzodiazepine and opioid palatabilitydependent appetite. Eur J Pharmacol 500: 37-49.

Cooper SJ, Francis RL (1979). Effects of acute or chronic administration of chlordiazepoxide on feeding parameters using two food textures in the rat. J Pharm Pharmacol 31: 743-746.

Corwin RL, Buda-Levin A (2004). Behavioral models of binge-type eating. Physiol Behav 82: 123-130.

Corwin RL (2006). Bingeing rats: a model of intermittent excessive behavior? Appetite 46: 11-15.

Cruz AP, Frei F, Graeff FG (1994). Ethopharmacological analysis of rat behavior on the elevated plus-maze. Pharmacol Biochem Behav 49: 171-176.

Culpepper-Morgan JA, Holt PR, LaRoche D, Kreek MJ (1995). Orally administered opioid antagonists reverse both mu and kappa opioid agonist delay of gastrointestinal transit in the guinea pig. Life Sci 56: 1187-1192.

de Zwaan M, Mitchell JE (1992). Opiate antagonists and eating behavior in humans: a review. J Clin Pharmacol 32: 1060-1072.

Despres JP (1993). Abdominal obesity as important component of insulin-resistance syndrome. Nutrition 9: 452-459.

Drazen DL, Vahl TP, D'Alessio DA, Seeley RJ, Woods SC (2006). Effects of a fixed meal pattern on ghrelin secretion: evidence for a learned response independent of nutrient status. Endocrinology 147: 23-30.

Druce MR, Neary NM, Small CJ, Milton J, Monteiro M, Patterson $\mathrm{M}$ et al (2006). Subcutaneous administration of ghrelin stimulates energy intake in healthy lean human volunteers. Int J Obes (Lond) 30: 293-296.

Emmerson PJ, Liu MR, Woods JH, Medzihradsky F (1994). Binding affinity and selectivity of opioids at mu, delta and kappa receptors in monkey brain membranes. J Pharmacol Exp Ther 271: $1630-1637$.

Falorni A, Kassi G, Murdolo G, Calcinaro F (1998). Controversies on humoral immune markers of insulin-dependent diabetes mellitus. J Pediatr Endocrinol Metab 11(Suppl 2): 307-317.

Fernandes C, File SE (1996). The influence of open arm ledges and maze experience in the elevated plus-maze. Pharmacol Biochem Behav 54: 31-40.

Flaherty CF, Checke S (1982). Anticipation of incentive gain. Anim Learn Behav 10: 177-182.

Flaherty CF, Rowan GA (1986). Successive, simultaneous, and anticipatory contrast in the consumption of saccharin solutions. J Exp Psychol Anim Behav Process 12: 381-393.
Flaherty CF, Coppotelli C, Grigson PS, Colin M, Flaherty JE (1995). Investigation of the devaluation interpretation of anticipatory negative contrast. J Exp Psychol Anim Behav Process 21: 229-247.

Fletcher BC, Pine KJ, Woodbridge Z, Nash A (2007). How visual images of chocolate affect the craving and guilt of female dieters. Appetite 48: 211-217.

Gluck ME (2006). Stress response and binge eating disorder. Appetite 46: 26-30.

Gola M, Bonadonna S, Doga M, Mazziotti G, Giustina A (2005). Cardiovascular risk in aging and obesity: is there a role for $\mathrm{GH}$. J Endocrinol Invest 28: 759-767.

Gonzalez VM, Vitousek KM (2004). Feared food in dieting and non-dieting young women: a preliminary validation of the Food Phobia Survey. Appetite 43: 155-173.

Guha PK, Villarreal D, Reams GP, Freeman RH (2003). Role of leptin in the regulation of body fluid volume and pressures. $A m \mathrm{~J}$ Ther 10: 211-218.

Hagan MM, Moss DE (1997). Persistence of binge-eating patterns after a history of restriction with intermittent bouts of refeeding on palatable food in rats: implications for bulimia nervosa. Int $J$ Eat Disord 22: 411-420.

Hagan MM, Chandler PC, Wauford PK, Rybak RJ, Oswald KD (2003). The role of palatable food and hunger as trigger factors in an animal model of stress induced binge eating. Int J Eat Disord 34: 183-197.

Hao J, Cabeza de Vaca S, Pan Y, Carr KD (2006). Effects of central leptin infusion on the reward-potentiating effect of D-amphetamine. Brain Res 1087: 123-133.

Harris RB, Martin RJ (1984). Recovery of body weight from below 'set point' in mature female rats. J Nutr 114: 1143-1150.

Hartz SM, Ben-Shahar Y, Tyler M (2001). Logistic growth curve analysis in associative learning data. Anim Cogn 3: 185-189.

Hoffman AR (2005). Treatment of the adult growth hormone deficiency syndrome: directions for future research. Growth Horm IGF Res 15(Suppl A): 48-52.

Hommel JD, Trinko R, Sears RM, Georgescu D, Liu ZW, Gao XB et al (2006). Leptin receptor signaling in midbrain dopamine neurons regulates feeding. Neuron 51: 801-810.

Howard CE, Porzelius LK (1999). The role of dieting in binge eating disorder: etiology and treatment implications. Clin Psychol Rev 19: 25-44.

Hudson JI, Hiripi E, Pope Jr HG, Kessler RC (2007). The prevalence and correlates of eating disorders in the National Comorbidity Survey Replication. Biol Psychiatry 61: 348-358.

Hunt T, Poulos CX, Cappell H (1988). Benzodiazepine-induced hyperphagia: a test of the hunger-mimetic model. Pharmacol Biochem Behav 30: 515-518.

Inoue K, Zorrilla EP, Tabarin A, Valdez GR, Iwasaki S, Kiriike N et al (2004). Reduction of anxiety after restricted feeding in the rat: implication for eating disorders. Biol Psychiatry 55: 1075-1081.

Jarosz PA, Sekhon P, Coscina DV (2006). Effect of opioid antagonism on conditioned place preferences to snack foods. Pharmacol Biochem Behav 83: 257-264.

June HL, Grey C, Warren-Reese C, Durr LF, Ricks-Cord A, Johnson A et al (1998). The opioid receptor antagonist nalmefene reduces responding maintained by ethanol presentation: preclinical studies in ethanol-preferring and outbred Wistar rats. Alcohol Clin Exp Res 22: 2174-2185.

Kales EF (1990). Macronutrient analysis of binge eating in bulimia. Physiol Behav 48: 837-840.

Kanarek RB, Orthen-Gambill N (1982). Differential effects of sucrose, fructose and glucose on carbohydrate-induced obesity in rats. J Nutr 112: 1546-1554.

Kanarek RB, Aprille JR, Hirsch E, Gualtiere L, Brown CA (1987). Sucrose-induced obesity: effect of diet on obesity and brown adipose tissue. Am J Physiol 253: R158-R166.

Kas MJ, van den BR, Baars AM, Lubbers M, Lesscher HM, Hillebrand JJ et al (2004). Mu-opioid receptor knockout mice 
show diminished food-anticipatory activity. Eur J Neurosci 20: 1624-1632.

Kauffman NA, Herman CP, Polivy J (1995). Hunger-induced finickiness in humans. Appetite 24: 203-218.

Kelley AE, Bakshi VP, Haber SN, Steininger TL, Will MJ, Zhang M (2002). Opioid modulation of taste hedonics within the ventral striatum. Physiol Behav 76: 365-377.

Kelley AE, Baldo BA, Pratt WE, Will MJ (2005). Corticostriatalhypothalamic circuitry and food motivation: integration of energy, action and reward. Physiol Behav 86: 773-795.

Kessler RC, McGonagle KA, Zhao S, Nelson CB, Hughes M, Eshleman $S$ et al (1994). Lifetime and 12-month prevalence of DSM-III-R psychiatric disorders in the United States. Results from the National Comorbidity Survey. Arch Gen Psychiatry 51: 8-19.

Knight LJ, Boland FJ (1989). Restrained eating: an experimental disentanglement of the disinhibiting variables of perceived calories and food type. J Abnorm Psychol 98: 412-420.

Landymore KM, Giles A, Wilkinson M (1992). Ex vivo determination of opiate antagonist binding at mu-opioid $\left(\left[{ }^{3} \mathrm{H}\right]-\mathrm{DAGO}\right)$ receptors in hypothalamic micropunches from maturing female rats: comparison between SDZ 210-096 and nalmefene. Neuropeptides 21: 175-182.

Levin BE, Richard D, Michel C, Servatius R (2000). Differential stress responsivity in diet-induced obese and resistant rats. Am J Physiol Regul Integr Comp Physiol 279: R1357-R1364.

MacDonald AF, Billington CJ, Levine AS (2003). Effects of the opioid antagonist naltrexone on feeding induced by DAMGO in the ventral tegmental area and in the nucleus accumbens shell region in the rat. Am J Physiol Regul Integr Comp Physiol 285: R999-R1004.

MacDonald AF, Billington CJ, Levine AS (2004). Alterations in food intake by opioid and dopamine signaling pathways between the ventral tegmental area and the shell of the nucleus accumbens. Brain Res 1018: 78-85.

Maffei M, Halaas J, Ravussin E, Pratley RE, Lee GH, Zhang Y et al (1995). Leptin levels in human and rodent: measurement of plasma leptin and ob RNA in obese and weight-reduced subjects. Nat Med 1: 1155-1161.

Mason BJ, Ritvo EC, Morgan RO, Salvato FR, Goldberg G, Welch B et al (1994). A double-blind, placebo-controlled pilot study to evaluate the efficacy and safety of oral nalmefene $\mathrm{HCl}$ for alcohol dependence. Alcohol Clin Exp Res 18: 1162-1167.

Mason BJ, Salvato FR, Williams LD, Ritvo EC, Cutler RB (1999). A double-blind, placebo-controlled study of oral nalmefene for alcohol dependence. Arch Gen Psychiatry 56: 719-724.

Michel ME, Bolger G, Weissman BA (1985). Binding of a new opiate antagonist, nalmefene, to rat brain membranes. Methods Find Exp Clin Pharmacol 7: 175-177.

Mitchell GL, Brunstrom JM (2005). Everyday dietary behaviour and the relationship between attention and meal size. Appetite 45: 344-355.

Olszewski PK, Levine AS (2007). Central opioids and consumption of sweet tastants: when reward outweighs homeostasis. Physiol Behav, in press.

Pico C, Oliver P, Sanchez J, Palou A (2003). Gastric leptin: a putative role in the short-term regulation of food intake. $\mathrm{Br} J$ Nutr 90: 735-741.

Pike KM, Dohm FA, Striegel-Moore RH, Wilfley DE, Fairburn CG (2001). A comparison of black and white women with binge eating disorder. Am J Psychiatry 158: 1455-1460.

Pliner P, Herman CP, Polivy J (1990). Palatability as a determinant of eating: Finickiness as a function of taste, hunger, and the prospect of good food. In: ED Capaldi and TL Powley (eds). Taste, Experience, and Feeding: Development and Learning. American Psychological Association: Washington, DC. pp 210-226.

Proulx K, Vahl TP, Drazen DL, Woods SC, Seeley RJ (2005). The effect of adrenalectomy on ghrelin secretion and orexigenic action. J Neuroendocrinol 17: 445-451.
Scacchi M, Pincelli AI, Cavagnini F (1999). Growth hormone in obesity. Int J Obes Relat Metab Disord 23: 260-271.

Sherwin RS, Hendler R, DeFronzo R, Wahren J, Felic P (1977). Glucose homeostasis during prolonged suppression of glucagon and insulin secretion by somatostatin. Proc Natl Acad Sci USA 74: $348-352$

Shizgal P, Fulton S, Woodside B (2001). Brain reward circuitry and the regulation of energy balance. Int J Obes Relat Metab Disord 25(Suppl 5): S17-S21.

Shrout PE, Fleiss JL (1979). Intraclass correlations: uses in assessing rater reliability. Psychol Bull 86: 420-428.

Smith DE, Marcus MD, Lewis CE, Fitzgibbon M, Schreiner P (1998). Prevalence of binge eating disorder, obesity, and depression in a biracial cohort of young adults. Ann Behav Med 20: 227-232.

Smith KS, Berridge KC (2007). Opioid limbic circuit for reward: interaction between hedonic hotspots of nucleus accumbens and ventral pallidum. J Neurosci 27: 1594-1605.

Specker S, de ZM, Raymond N, Mitchell J (1994). Psychopathology in subgroups of obese women with and without binge eating disorder. Compr Psychiatry 35: 185-190.

Stirling LJ, Yeomans MR (2004). Effect of exposure to a forbidden food on eating in restrained and unrestrained women. Int J Eat Disord 35: 59-68.

Taber MT, Zernig G, Fibiger HC (1998). Opioid receptor modulation of feeding-evoked dopamine release in the rat nucleus accumbens. Brain Res 785: 24-30.

Taylor AE, Hubbard J, Anderson EJ (1999). Impact of binge eating on metabolic and leptin dynamics in normal young women. $J$ Clin Endocrinol Metab 84: 428-434.

Tschop M, Smiley DL, Heiman ML (2000). Ghrelin induces adiposity in rodents. Nature 407: 908-913.

Unterwald EM, Tsukada H, Kakiuchi T, Kosugi T, Nishiyama S, Kreek MJ (1997). Use of positron emission tomography to measure the effects of nalmefene on D1 and D2 dopamine receptors in rat brain. Brain Res 775: 183-188.

Wajchenberg BL (2000). Subcutaneous and visceral adipose tissue: their relation to the metabolic syndrome. Endocr Rev 21: 697-738.

Ward HG, Nicklous DM, Aloyo VJ, Simansky KJ (2006). Mu-opioid receptor cellular function in the nucleus accumbens is essential for hedonically driven eating. Eur J Neurosci 23: $1605-1613$

Wardle J, Guthrie CA, Sanderson S, Rapoport L (2001). Development of the children's eating behaviour questionnaire. J Child Psychol Psychiatry 42: 963-970.

Woolley JD, Lee BS, Fields HL (2006). Nucleus accumbens opioids regulate flavor-based preferences in food consumption. Neuroscience 143: 309-317.

Wortley KE, del Rincon JP, Murray JD, Garcia K, Iida K, Thorner $\mathrm{MO}$ et al (2005). Absence of ghrelin protects against early-onset obesity. J Clin Invest 115: 3573-3578.

Yanovski SZ (2003). Binge eating disorder and obesity in 2003: could treating an eating disorder have a positive effect on the obesity epidemic? Int J Eat Disord 34(Suppl): S117-S120.

Yeomans MR, Gray RW (2002). Opioid peptides and the control of human ingestive behaviour. Neurosci Biobehav Rev 26: 713-728.

Yeomans MR, Wright P (1991). Lower pleasantness of palatable foods in nalmefene-treated human volunteers. Appetite 16: 249-259.

Yeomans MR, Wright P, Macleod HA, Critchley JA (1990). Effects of nalmefene on feeding in humans. Dissociation of hunger and palatability. Psychopharmacology (Berl) 100: 426-432.

Zorrilla EP, Valdez GR, Nozulak J, Koob GF, Markou A (2002). Effects of antalarmin, a CRF type 1 receptor antagonist, on anxiety-like behavior and motor activation in the rat. Brain Res 952: 188-199. 